\title{
REVIEW \\ Control of energy expenditure in humans
}

\author{
KR Westerterp
}

Energy expenditure is determined by body size and body composition and by food intake and physical activity. Body size and body composition are the determinants of resting energy expenditure. Higher weight results in higher energy requirement through a higher resting requirement because of a higher maintenance cost of a larger body. Activity-induced energy expenditure is the most variable component of total energy expenditure. Smaller and leaner subjects generally move more as activity energy expenditure in larger subjects is not higher in proportion to the cost of moving with a higher body weight. Food intake induces changes in energy expenditure as a function of changes in body size and body composition. In addition, energy restriction induces an adaptive reduction of energy expenditure through a lowering of tissue metabolism and a reduction of body movement. An exercise-induced increase in activity expenditure is a function of the training status. In untrained subjects, exercise induces a larger increase in total energy expenditure than can be attributed to the energy cost of a training program. Trained subjects have a higher performance at the same expenditure through a higher exercise economy.

European Journal of Clinical Nutrition (2017) 71, 340-344; doi:10.1038/ejcn.2016.237; published online 30 November 2016

\section{INTRODUCTION}

Energy expenditure in humans is determined by body size and body composition, environment and behavior. A larger body, especially a larger fat-free mass, requires more maintenance and thus induces a higher basal metabolic rate or resting energy expenditure. The main environmental determinant of energy expenditure is ambient temperature, where energy expenditure increases in a cold environment through shivering and in a hot environment through panting. Behavioral determinants of energy expenditure include food intake and physical activity. In normal daily life, environmental factors like ambient temperature are negligible. We generally choose our environment to feel comfortable. We stay in the thermal neutral zone by controlling the temperature of our homes and dress according to climatic conditions when going out. Thus, this review is restricted to determinants including subject characteristics, food intake and physical activity.

Total energy expenditure (TEE) can be split in three components: maintenance or resting energy expenditure (REE); energy expenditure for the processing of ingested food or diet-induced energy expenditure (DEE); and activity-induced energy expenditure (AEE). Here, control of energy expenditure is reviewed by comparing TEE and the three components in relation to differences for the subject characteristics body size and body composition, followed by reviewing effects of changes in food intake and changes in physical activity on energy expenditure.

\section{BODY SIZE, BODY COMPOSITION AND ENERGY EXPENDITURE}

From birth, children grow in weight and height, reaching adult values around the age of 18 years. Initially, energy requirement is mainly determined by growth and energy expenditure for body maintenance. ${ }^{1}$ Activity energy expenditure as a fraction of TEE increases from $20 \%$ at age 1 to $\sim 35 \%$ at age 18 . $^{2}$ The increase is reflected in an increase of the physical activity index (PAI=TEE/ REE) from 1.4 to 1.75 . Here, the focus is on body size, body composition and energy expenditure in subjects where adult height is reached, that is, age of 18 years and older.

At adult age, the largest component of TEE for a moderately active subject is for body maintenance as measured under resting conditions. DEE represents about $10 \%$ of the total amount of energy ingested for an average diet with 10-15 energy $\%$ from protein, 30-35 energy\% from fat and the remaining energy from carbohydrate. $^{3}$ Thus, DEE is $10 \%$ of TEE when one eats according to what one needs. AEE is the most variable component of TEE and depends on a subject's lifestyle (Table 1). For a moderately active subject with a PAI of $1.70-1.99$, AEE is $30-40 \%$ of TEE.

Body size mainly affects the maintenance component of TEE, through the relation between body size and fat-free mass. Larger body size implies a larger fat-free mass (Figure 1). Taller subjects have a larger fat-free mass than subjects with a short stature and fat-free mass is larger in overweight and obese subjects than in lean subjects with the same stature. Thus, REE is generally higher in men than in women of similar weight and height and increases with weight gain at adult age.

The activity component of TEE seems to be similarly affected by body size as REE, judging the similarity of the PAI for subjects categorized according to body mass index (Figure 2). The average PAl is around 1.80 for all body mass index categories except the very highest, as observed before in an analysis of 319 measurements of PAI in adults aged 18-64 years. ${ }^{4}$ Thus, TEE increases with body mass as a function of fat-free mass. ${ }^{5,6}$ Only when one reaches the morbid obese state, there is no further increase of AEE.

The similarity of the mean value of the PAl in subjects over a wide range of body size does not imply similar body movement as well. Subjects with a higher body mass index, that is, fatter subjects, generally move less because of the higher cost of

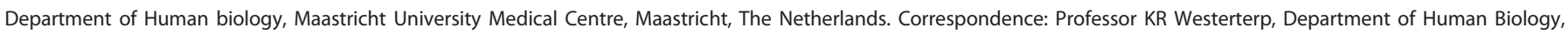
Maastricht University Medical Centre, Vakgroep Humane Biologie, PO Box 616, Maastricht 6200 MD, The Netherlands. 
weight-bearing activities. The higher AEE in fatter subjects is not higher in proportion to the higher cost for weight-bearing activities. Obese subjects move slower and have lower endurance. $^{7,8}$ Excess body fat prevents optimal physical performance. $^{9}$

In conclusion, energy expenditure is higher in larger subjects due to higher energy expenditure for maintenance. However, smaller and leaner subjects generally move more as activity energy expenditure in larger subjects is not higher in proportion to the cost of moving with a higher body weight.

\section{CHANGES IN FOOD INTAKE AND ENERGY EXPENDITURE}

Food intake affects energy expenditure through effects on all three components of TEE. A change in food intake affects energy expenditure primarily through its effect on DEE, where DEE is about $10 \%$ of the total amount of energy ingested for an average diet as mentioned above. Thus, increasing intake increases TEE through an increase in DEE and vice versa. In addition, food intake affects REE and AEE as a function of energy balance where effects of overfeeding are different from energy restriction.

Overfeeding induces weight gain where, in normal weight subjects, most of the weight gain is as fat but at least $20 \%$ of weight gain is as fat-free mass. ${ }^{10,11}$ Overfeeding increases REE as a function of the change in fat-free mass. There does not seem to be an additional effect of overfeeding on physical activity as reviewed before. ${ }^{12}$ Doubly labeled water studies showed no change in PAl other than a decrease during massive overfeeding (Figure 3). A recent study suggested a specific effect of overfeeding on energy expenditure in relation to the protein content of the diet. ${ }^{13}$ However, the instantaneous $0.54 \mathrm{MJ}$ per day increase in energy expenditure by overfeeding subjects with $130 \mathrm{~g}$ protein per day was exactly as expected from the increased DEE of

Table 1. Classification of the PAl, total energy expenditure as a multiple of resting energy expenditure, in relation to lifestyle. ${ }^{47}$

\begin{tabular}{|c|c|}
\hline Lifestyle & $P A l$ \\
\hline Sedentary or light active & $1.40-1.69$ \\
\hline Active or moderately active & $1.70-1.99$ \\
\hline Vigorous or vigorously active & $2.00-2.40^{\mathrm{a}}$ \\
\hline
\end{tabular}

the additional protein ingested. The DEE value of protein is 20 $30 \%$ of the energy content. ${ }^{3}$ Thus, adding $130 \mathrm{~g}$ protein, with an energy content of $2.08 \mathrm{MJ}$, to daily intake increases DEE and thus TEE with 0.42-0.62 MJ per day. Similarly, exchanging fat for protein in an isoenergetic diet increased energy expenditure with an amount equivalent to the difference in processing costs of fat, $0-3 \%$ of the energy content and the higher processing costs of protein. ${ }^{14}$ Overfeeding does not induce adaptive thermogenesis, a change in energy expenditure not attributable to a change in body size and to the DEE of the additional food to be ingested.

Energy restriction does induce adaptive changes in energy expenditure. The classical Minnesota Experiment, where energy intake of normal weight men was reduced with $8 \mathrm{MJ}$ per day for 24 weeks, resulted in a new energy balance at $<50 \%$ of maintenance requirement at the start of the intervention. ${ }^{15}$ Most of the starvation-induced reduction in TEE could be explained by decreased maintenance costs of a smaller body, reduction in the processing costs of the decreased amount of food to be ingested and reduction of the costs of moving a smaller body. However, $11 \%$ of the reduction in TEE was due to an adaptive change in REE and $35 \%$ of the reduction in TEE was due to an adaptive change in AEE. The adaptive change in REE was explained by a lower tissue metabolism and subjects moving less explained adaptive change in AEE. Similar but less pronounced adaptations in energy expenditure have been observed in overweight and obese subjects on an energy-restricted diet. Energy restriction induces a reduction in REE below predicted values, as based on the new body composition reached after underfeeding-induced weight loss. ${ }^{16-19}$ The REE reduction in obese subjects losing $10-20 \%$ of initial weight, adjusted for changes in body composition, ranges between 3 and $6 \%$ of the initial TEE value. Van Gemert et al. ${ }^{20}$ observed in morbid obese subjects losing on average one-third of initial weight, an average reduction of $7 \%$ at 1 year after the start of weight loss and of $4 \%$ when weight loss was maintained for more than 3 years. The adaptive AEE reduction induced by restricting energy intake in overweight and obese subjects is larger, and can be explained by a reduction in body movement and an increase in muscle efficiency. ${ }^{17,21}$ However, Camps et al. ${ }^{21}$ observed an energy restriction-induced adaptive reduction of $\mathrm{AEE}$ that is not sustained when energy intake meets again TEE. ${ }^{21}$ The energy restriction-induced adaptive reduction of REE persists perhaps indefinitely. ${ }^{17,20}$

The difference in effect of overfeeding and energy restriction on REE and AEE probably is a consequence of natural selection. Compensatory mechanisms sparing energy to decrease weight loss and increase weight gain had survival value in an

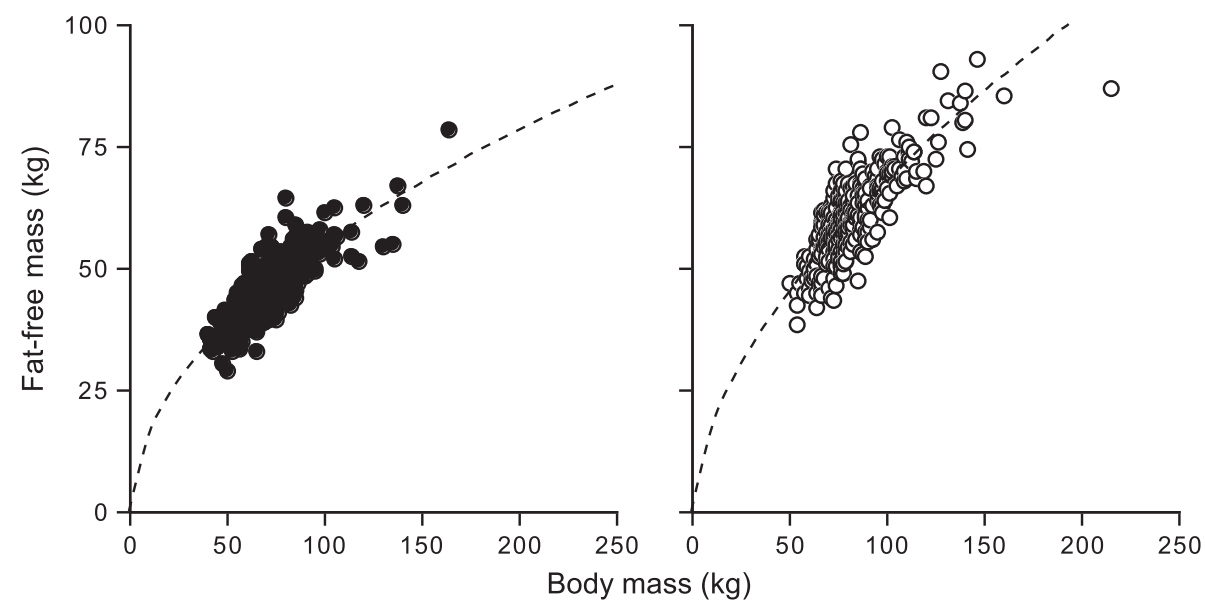

Figure 1. Fat-free mass plotted against body mass for adult subjects; age 18-50 years, with an exponential fitted curve, left figure (closed dots) for women and right figure (open dots) for men (data from Speakman and Westerterp ${ }^{29}$ ). 


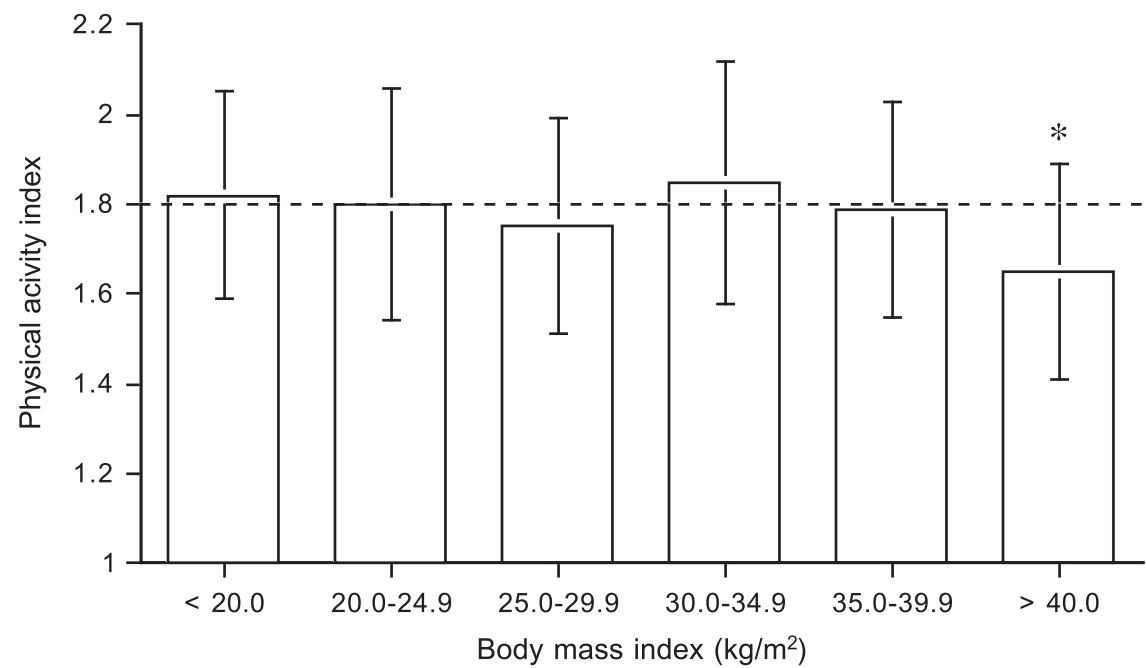

Figure 2. Physical activity index, total energy expenditure as a multiple of resting energy expenditure, and body mass index (data from Westerterp and Speakman $\left.{ }^{38}\right)$. *Significantly different from the other body mass index categories $(P<0.05)$.

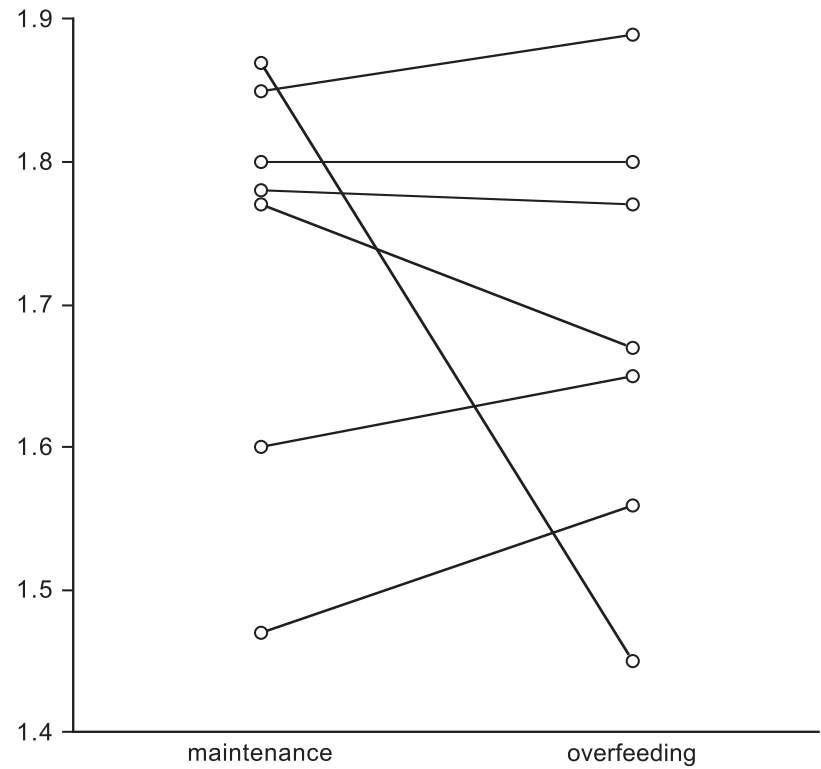

Figure 3. Physical activity index, total energy expenditure as a multiple of resting energy expenditure, before and during overfeeding (data from references ${ }^{39-45}$ ).

environment where food was not always available, as during ancestral life. ${ }^{22}$ Humans have developed many adaptations to hunger but not for overconsumption. Never in human history, there has been continual food abundance as during the last 50 years. Thus, we nowadays live in an environment where overeating is common, with the consequent risk for getting overweight and obese. ${ }^{23}$

\section{CHANGES IN PHYSICAL ACTIVITY AND ENERGY EXPENDITURE}

Exercise training is an effective strategy to increase TEE, especially by increasing AEE. ${ }^{24}$ However, under some conditions, an exerciseinduced increase in physical activity is compensated by a decrease in non-training physical activity. One condition is a negative energy balance. Kempen et al. ${ }^{25}$ observed no effect of exercise

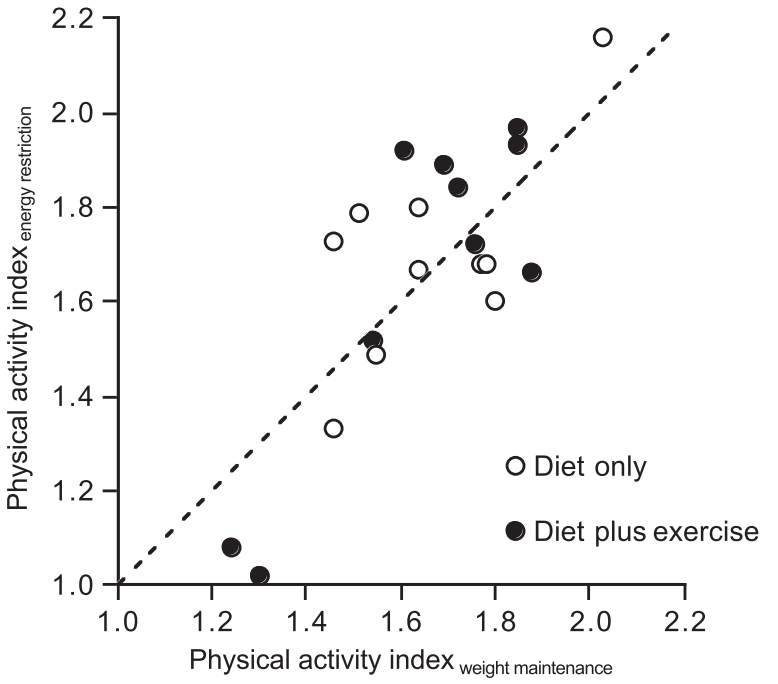

Figure 4. Physical activity index, total energy expenditure as a multiple of resting energy expenditure, during energy-restricted diet with or without exercise as a function of the value at weight maintenance. The dotted line is the line of identity (data from Kempen et $a l^{25}$ ).

training on the PAI when training was combined with an energyrestricted diet (Figure 4). It seems to be difficult to comply with an exercise program without compensating for and exercise-induced increase in energy expenditure by increasing energy intake. ${ }^{26}$ If not, at a negative energy balance, exercise-induced energy expenditure is compensated by a reduction in nonexercise activity. ${ }^{27,28}$ Another condition where an exercise-induced increase in physical activity is compensated by a decrease in non-training physical activity is in older subjects. Physical activity decreases with increasing age, on average from about age of 50 years onwards. ${ }^{29}$ In parallel, exercise training studies show a compensatory decrease in non-training physical activity in older subjects. $^{30}$ Then, maintenance of energy balance might explain why exercise training does not increase AEE. Exposing young adults and subjects over 50 years to the same 10-day strenuous hill walking activity induced an increase in food intake in the 


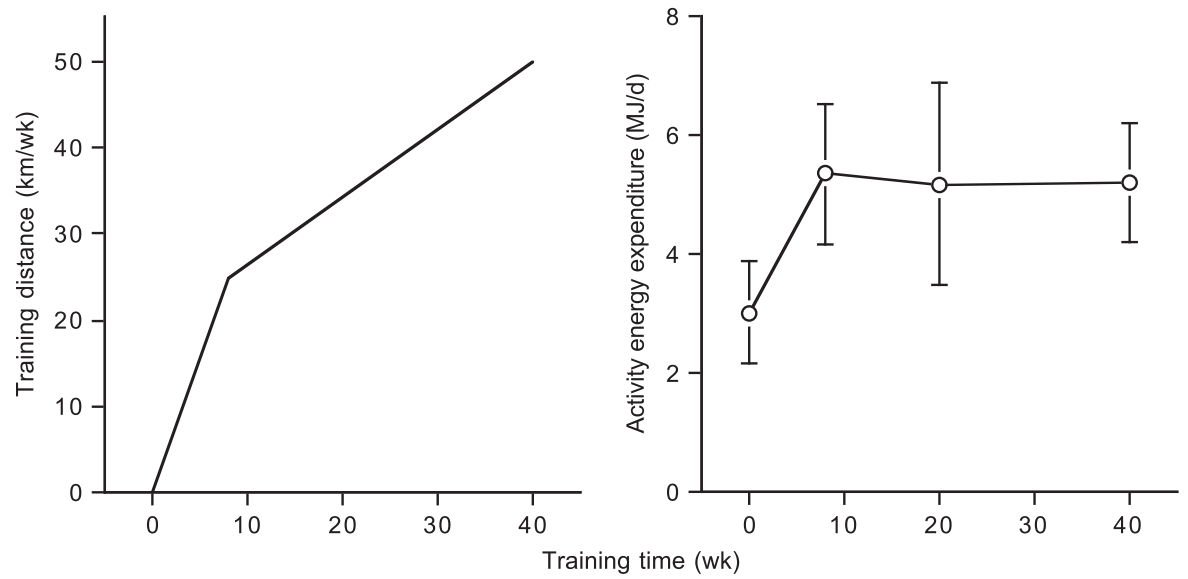

Figure 5. Training distance and activity energy expenditure over a 40-week interval in untrained subjects, training to run a half-marathon competition (data from Westerterp et al. ${ }^{46}$ ).

young subjects, whereas the older subjects ate $4 \mathrm{MJ}$ per day less than the average $21 \mathrm{MJ}$ per day energy expenditure. ${ }^{31}$ Similarly, older male cyclists sustained near-maximal rates of energy expenditure during prolonged cycling, but were unable to upregulate energy intake to maintain energy balance. Despite the presence of increased motivation to eat, a more profound counteracting physiological stimulus inhibiting increases in energy intake was present. ${ }^{32}$

Under conditions where exercise training does affect TEE through an increase in $A E E$, that is, in healthy young adults under ad libitum food conditions, the increase in AEE is a function of the training status of the subjects. In untrained subjects, the initial exercise-induced increase in AEE is nearly twice the estimated cost of the training. ${ }^{33}$ Exercise training subsequently increases exercise economy. We observed an increase in AEE of about $15 \mathrm{MJ}$ per week in untrained subjects, preparing to run a half-marathon (Figure 5). The increase occurred in the initial phase of the training, where AEE did not show a further increase when the training distance was subsequently doubled from 25 to $50 \mathrm{~km}$ per week. The observed increase in AEE of $15 \mathrm{MJ}$ was in line with the costs of running $50 \mathrm{~km}$ for the subjects with an average body mass of nearly $70 \mathrm{~kg}$. Exercise training can even decrease walking cost in older adults, delaying the age-related decline in walking economy. $^{34}$

\section{DISCUSSION}

The main determinants of energy expenditure are body size and body composition, food intake and physical activity. Food intake and physical activity affect energy expenditure directly and indirectly, the latter through the effect of food intake and physical activity on body size and body composition. Energy expenditure reaches minimal values in subjects with anorexia nervosa and maximal values in morbid obese subjects or elite endurance athletes. In anorectic women, TEE can be below 5 MJ per day. ${ }^{35}$ Undereating induces weight loss, resulting in a reduction in body size with a consequent reduction in REE. Chronic energy deficiency reduces $A E E$ through a lower physical capacity with the loss of muscle mass. ${ }^{15,35}$ Thus, TEE is less than half the value of 10 MJ per day for a women with average size and PAI. Chronic overeating induces weight gain, resulting in TEE values over $15 \mathrm{MJ}$ per day for women and $20 \mathrm{MJ}$ per day for men with morbid obesity, at least $50 \%$ higher than the value at average size and PAI.

The reduction in TEE during energy restriction reduces weight loss. To maximize weight loss for obesity treatment, studies were designed on the effect of intermittent versus continuous energy restriction. However, although intermittent energy restriction consistently reduces body weight and adiposity, it does not seem to be superior to continuous energy restriction for weight loss. ${ }^{36}$ Adaptive reduction of TEE is similar at both regimens of energy restriction.

The increase in TEE through physical activity is suggested to be constrained. Pontzer et $a l^{37}$ concluded, from a comparative analysis of TEE and physical activity data, TEE increases with physical activity al low activity levels but plateaus with higher activity levels. They suggested a model of constrained TEE with metabolic adaptations to physical activity. An explanation is the difference in exercise economy between subjects with a low PAI being untrained and subjects with a high PAl being trained. The training-induced increase in exercise economy limits the effect of an increase in physical activity on TEE and thus explains the curvilinear relation between physical activity and TEE as observed by Pontzer et $\mathrm{al}^{37}$

In conclusion, maintenance metabolism is the largest component of TEE, especially at young and old age. Activity energy expenditure is the most variable component of TEE and can be increased when food intake allows. Energy expenditure increases with weight gain at adult age through a consequent increase in maintenance metabolism. Smaller and leaner subjects generally move more as activity energy expenditure in larger subjects is not higher in proportion to the cost of moving with a higher body weight. Energy restriction and overfeeding induce changes in energy expenditure as a function of changes in body size and body composition. In addition, energy restriction induces an adaptive reduction of energy expenditure through a lowering of tissue metabolism and a reduction of body movement. An exercise-induced increase in activity expenditure is a function of the training status.

\section{CONFLICT OF INTEREST}

The author declares no conflict of interest.

\section{REFERENCES}

1 De Bruin NC, Degenhart HJ, Gàl S, Westerterp KR, Stijnen T, Visser HK. Energy utilization and growth in breast-fed and formula-fed infants measured prospectively during the first year of life. Am J Clin Nutr 1998; 67: 885-896.

2 Butte NF, Ekelund U, Westerterp KR. Assessing physical activity using wearable monitors: measures of physical activity. Med Sci Sports Exerc 2012; 44(Suppl 1): S5-S12.

3 Tappy L. Thermic effect of food and sympathetic nervous system activity in humans. Reprod Nutr Rev 1996; 36: 391-397. 
4 Prentice AM, Black AE, Coward WA, Cole TJ. Energy expenditure in overweight and obese adults in affluent societies: an analysis of 319 doubly-labelled water measurements. Eur J Clin Nutr 1996; 50: 93-97.

5 Webb P. Energy expenditure and fat-free mass in men and women. Am J Clin Nutr 1981; 34: 1816-1826.

6 Schoeller DA, Fjeld CR. Human energy metabolism: what have we learned from the doubly labeled water method? Annu Rev Nutr 1991; 11: 355-373.

7 Kim JW, Seo DI, Swearingin B, So WY. Association between obesity and various parameters of physical fitness in Korean students. Obes Res Clin Pract 2013; 7: e67-e74.

8 Pataky Z, Armand S, Müller-Pinget S, Golay A, Allet L. Effects of obesity on functional capacity. Obesity 2014; 22: 56-62.

9 Westerterp KR. Daily physical activity as determined by age, body mass and energy balance. Eur J Appl Physiol 2015; 115: 1177-1184.

10 Forbes GB. Lean body mass-body fat interrelationships in humans. Nutr Rev 1987; 45: 225-231.

11 Hall KD. Body fat and fat-free mass inter-relationships: Forbes's theory revisited. $\mathrm{Br}$ J Nutr 2007; 97: 1059-1063.

12 Westerterp KR. Physical activity, food intake and body weight regulation: insights from doubly labeled water studies. Nutr Rev 2010; 68: 148-154.

13 Bray GA, Redman LM, De Jonge L, Covington J, Rood J, Brock C et al. Effect of protein overfeeding on energy expenditure measured in a metabolic chamber. Am J Clin Nutr 2015; 101: 496-505.

14 Hochstenbach-Waelen A, Veldhorst MA, Nieuwenhuizen AG, WesterterpPlantenga MS, Westerterp KR. Comparison of 2 diets with either $25 \%$ or $10 \%$ of energy as casein on energy expenditure, substrate balance and appetite profile. Am J Clin Nutr 2009; 89: 831-838.

15 Keys A, Brozek J, Henschel A, Mickelsen O, Taylor HL. The Biology of Human Starvation. University of Minnesota Press: Minneapolis, USA, 1950.

16 Major GC, Doucet E, Trayhurn P, Astrup A, Tremblay A. Clinical significance of adaptive thermogenesis. Int J Obes 2007; 31: 204-212.

17 Rosenbaum M, Hirsch J, Gallagher DA, Leibel RL. Long-term persistence of adaptive thermogenesis in subjects who have maintained a reduced body weight. Am J Clin Nutr 2008; 88: 906-912.

18 Schwartz A, Kuk JL, Lamothe G, Doucet E. Greater than predicted decrease in resting energy expenditure and weight loss: results from a systematic review. Obesity 2012; 20: 2307-2310.

19 Camps SG, Verhoef SP, Westerterp KR. Weight loss, weight maintenance and adaptive thermogenesis. Am J Clin Nutr 2013; 97: 990-994.

20 Van Gemert WG, Westerterp KR, Greve JM, Soeters PB. Reduction of sleeping metabolic rate after vertical banded gastroplasty. Int J Obes 1998; 22: 343-348.

21 Camps SG, Verhoef SP, Westerterp KR. Weight loss-induced reduction in physical activity recovers during weight maintenance. Am J Clin Nutr 2013; 98: 917-923.

22 Dulloo AG, Schutz Y. Adaptive thermogenesis in resistance to obesity therapies: issues in quantifying thrifty energy expenditure phenotypes in humans. Curr Obes Rep 2015; 4: 230-240.

23 Heitmann BL, Westerterp KR, Loos RJ, Sørensen TI, O'Dea K, McLean P et al. Obesity: lessons from evolution and the environment. Obes Rev 2012; 13: 910-922.

24 Washburn RA, Lambourne K, Szabo AN, Herrmann SD, Honas JJ, Donelly JE. Does increased prescribed exercise alter non-exercise physical activity/energy expenditure in healthy adults? A systematic review. Clin Obes 2013; 4: 1-20.

25 Kempen KP, Saris WH, Westerterp KR. Energy balance during an 8-wk energyrestrictive diet with and without exercise in obese women. Am J Clin Nutr 1995; 62: 722-729.

26 Thomas DM, Bouchard C, Church T, Slentz C, Kraus WE, Redman LM et al. Why do individuals not lose more weight from an exercise intervention at a defined dose? An energy balance analysis. Obes Rev 2012; 13: 835-847.

27 Pontzer $\mathrm{H}$. Constrained total energy expenditure and the evolutionary biology of energy balance. Exerc Sport Sci Rev 2015; 43: 110-116.

28 Melanson EL, Keadle SK, Donelly JE, Braun B, King NA. Resistance to exerciseinduced weight loss: compensatory behavioral adaptations. Med Sci Sports Exerc 2013; 45: 1600-1609.

29 Speakman JR, Westerterp KR. Associations between energy demands, physical activity and body composition in adult humans between 18 and 96 y of age. Am J Clin Nutr 2010; 92: 826-834.
30 Westerterp KR, Plasqui G. Physical activity and human energy expenditure. Curr Opin Clin Nutr Metab Care 2004; 7: 607-613.

31 Ainsli PN, Campbell IT, Frayn KN, Humphreys SM, MacLaren DP, Reilly T et al. Energy balance, metabolism, hydration, and performance during strenuous hill walking: the effect of age. J Appl Physiol 2002; 93: 714-723.

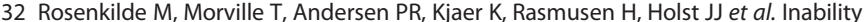
to match energy intake with energy expenditure at sustained near-maximal rates of energy expenditure in older men during a 14-d cycling expedition. Am J Clin Nutr 2015; 102: 1398-1405.

33 Van Etten LM, Westerterp KR, Verstappen FT, Boon BJ, Saris WH. Effect of an 18-wk weight-training program on energy expenditure and physical activity. J Appl Physiol 1997; 82: 298-304.

34 Valenti G, Bonomi AG, Westerterp KR. Multicomponent fitness training improves walking economy in older adults. Med Sci Sports Exerc 2016; 48: 1365-1370.

35 Bouten CV, Van Marken Lichtenbelt WD, Westerterp KR. Body mass index and daily physical activity in anorexia nervosa. Med Sci Sports Exerc 1996; 28: 967-973.

36 Seimon RV, Roekenes JA, Zibellini J, Zhu B, Gibson AA, Hills AP et al. Do intermittent diets provide physiological benefits over continuous diets for weight loss? A systematic review of clinical trials. Mol Cell Endocrinol 2015; 418: 153-172.

37 Pontzer H, Durazo-Arvizu R, Dugas LR, Plange-Rhule J, Bovet P, Forrester TE et al. Constrained total energy expenditure and metabolic adaptation to physical activity in adult humans. Curr Biol 2016; 26: 410-417.

38 Westerterp KR, Speakman JR. Physical activity energy expenditure has not declined since the $1980 \mathrm{~s}$ and matches energy expenditures of wild mammals. Int J Obes 2008; 32: 1256-1263.

39 Bandini LG, Schoeller DA, Edwards J, Young VR, Oh SH, Dietz WH. Energy expenditure during carbohydrate overfeeding in obese and nonobese adolescents. Am J Physiol 1989; 256: E357-E367.

40 Roberts SB, Young VR, Fuss P, Fiatarone MA, Richard B, Rasmussen $\mathrm{H}$ et al. Energy expenditure and subsequent nutrient intakes in overfed young men. Am J Physiol 1990; 259: R461-R469.

41 Diaz EO, Prentice AM, Goldberg GR, Murgatroyd PR, Coward WA. Metabolic response to experimental overfeeding in lean and overweight healthy volunteers. Am J Clin Nutr 1992; 56: 641-655.

42 Pasquet $\mathrm{P}$, Brigant L, Froment A, Koppert GA, Bard D, de Garine I et al. Massive overfeeding and energy balance in men: the Guru Walla model. Am J Clin Nutr 1992; 56: 483-490.

43 Joosen AMCP, Bakker AHF, Westerterp KR. Metabolic efficiency and energy expenditure during short-term overfeeding. Physiol Behav 2005; 85: 593-597.

44 Siervo M, Frühbeck G, Dixon A, Goldberg GR, Coward WA, Murgatroyd PR et al. Efficiency of autoregulatory homeostatic responses to imposed caloric excess in lean men. Am J Physiol 2008; 294: E416-E424.

45 Apolzan JW, Bray GA, Smith SR, De Jonge L, Rood J, Han H et al. Effect of weight gain induced by controlled overfeeding on physical activity. Am J Physiol 2014; 307: E1030-E1037.

46 Westerterp KR, Meijer GA, Janssen EM, Saris WH, Ten Hoor F. Long-term effect of physical activity on energy balance and body composition. Br J Nutr 1992; 68: 21-30.

47 FAO/WHO/UNU. Human Energy Requirements. 2004, FAO Food and nutrition report series 1: Rome, Italy.

(c) (1) $\Theta$ This work is licensed under a Creative Commons Attributioncc. NonCommercial-NoDerivs 4.0 International License. The images or other third party material in this article are included in the article's Creative Commons license, unless indicated otherwise in the credit line; if the material is not included under the Creative Commons license, users will need to obtain permission from the license holder to reproduce the material. To view a copy of this license, visit http:// creativecommons.org/licenses/by-nc-nd/4.0/

(c) The Author(s) 2017 